\title{
A closed modified V-shaped uniplanar triple band ACS fed antenna for wireless applications
}

\author{
Anuj Kumar ${ }^{1}$, Anukul Jindal' ${ }^{2}$, Apurva Singh ${ }^{3}$, Reshma Roy $^{4}$, Om Prakash Kumar ${ }^{5}$, Tanweer Ali \\ ${ }^{1,2,5,6}$ Department of Electronics \& Communication Engineering, Manipal Institute of Technology, \\ Manipal Academy of Higher Education, India \\ ${ }^{3}$ KPIT Technologies, India \\ ${ }^{4}$ Wipro Limited, India
}

\begin{tabular}{l}
\hline \hline Article Info \\
\hline Article history: \\
Received Jan 23, 2020 \\
Revised Mar 16, 2020 \\
Accepted Apr 12, 2020 \\
\end{tabular}

Keywords:

ACS fed

Radiating patch

Triple band

Uniplanar

\begin{abstract}
In the proposed paper, a uniplanar asymmetric coplanar strip (ACS) fed antenna with closed V-shaped radiating patch of size $26 \times 15 \times 1.6 \mathrm{~mm}^{3}$ printed on FR4 substrate with loss tangent $(\boldsymbol{\delta})=0.02$, height $(\mathrm{h})=1.6 \mathrm{~mm}$, and dielectric constant of 4.4 covering WiMAX, X-band and WLAN applications is presented. The closed V-shaped radiating patch is formed by joning two rectangular stubs. The remaining radiating part is obtained by adding rectangular strips to feed to obtained multiband operation. The advantage of this structure is that it forms simple configuration as well as helps the antenna attaining three distinict useful frequency band with good impedance matching for $S_{11}<-10 \mathrm{~dB}$ criteria. The proposed antenna operates at 3.1 (WiMAX), 5.0 (WLAN) and 9.9 (X-band) $\mathrm{GHz}$ in simulation. Under measurement the proposed antenna shows multiband phenomenon at 3.2, 5.3 and $9.7 \mathrm{GHz}$, respectively. The antenna exhibits simulated gain of 2.51, 1.18 and $1.96 \mathrm{~dB}$ at 3.1, 5.0 and $9.9 \mathrm{GHz}$. The key parameters of the antenna like length and width of the multi-branched strips are optimized to get the multiband operation. The evolution and optimization process is dealt in detail with the help of $S_{11}$, VSWR, current distributions, radiation patterns and gain.
\end{abstract}

This is an open access article under the CC BY-SA license.

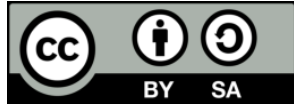

\section{Corresponding Author:}

Tanweer Ali,

Department of Electronics \& Communication Engineering,

Manipal Institute of Technology,

Manipal Academy of Higher Education, Manipal, India.

Email: tanweer.ali@manipal.edu

\section{INTRODUCTION}

The recent advancements in the field of wireless communications has led to the development of different types of antennas. There is a necessity for integrating the various communication devices such as WLAN, WiMAX and LTE in a single wireless gadget (i.e. smart phones) [1-5]. Due to this, multiband antennas are being widely used in order to cover multiple frequency bands. Different types of antennas designed to cover the wireless applications are monopole, dipole, metamaterial, dielectric resonator antena etc. Multi band antennas not only cover various applications but also display features like compact size, low costand high datarates [6-10].

The asymmetric coplanar strip (ACS) fed antennas has recently gained tremendous popularity to the antenna design engineers due to their size reduction techniques along with its wide impedance bandwidth, desired radiation properties (gain and effeciency) and simple structures [11-13]. ACS method provides a compact and uniplanar antenna since it has a single ground plane compared to other techniques [14, 15]. 
In order to decrease the overall size of the patch antenna, designs are proposed using the concept of asymmetric coplanar strip fed technique [16-18]. In comparison to a coplanar waveguide (CPW) antenna, an ACS fed antenna will reportedly consume only $50 \%$ of area due to only half ofthe ground plane of coplanar waveguide fed structure [19, 20].

Recently numerous ACS fed multiband antenna are proposed in this regard [16-25]. An ACS fed antenna of size $14 \times 20 \times 1.6 \mathrm{~mm}^{3}$ operating at $2.35,3.5$ and $5.25 \mathrm{GHz}$ is proposed in [16]. The radiating element is made up of Y-shaped patch with rectangular feed. Brijesh Mishra et al. [17] proposed a microstrip patch antenna for WLAN/WiMax applications, operating at frequencies 3.6 and $5.4 \mathrm{GHz}$ of size $60 \times 36 \times 1.6 \mathrm{~mm}^{3}$. The antenna comprises of a single slot and inverted L-shaped slot. Samson et al. [18], proposed a dual band monopole antenna having a size of $19.1 \times 22.6 \times 1.6 \mathrm{~mm}^{3}$ and resonant frequencies of 2,3 and $5.2 \mathrm{GHz}$. An ACS fed antenna loaded with mirrored $\mathrm{S}$ and L-shaped strips of size $11.5 \times 26 \times 1.6 \mathrm{~mm}^{3}$, with resonant frequencies of $2.35,3.45$ and $5.2 \mathrm{GHz}$ is proposed in [19]. The proposed antenna consists of a meandered mirrored S-shaped strip and an electrical L-shaped radiating patch. Ansal et al. [20], proposed a novel CB (conductor backed) ACS-fed dual band antenna operating at frequencies 2.45 and $5 \mathrm{GHz}$ of size $25 \times 17.5 \times 1.6 \mathrm{~mm}^{3}$. The antenna consists of a radiating L-shaped strip, ground plane and a modified truncated ground plane.

Arvind Kumar et al. [21] proposed a compact uniplanar ACS fed antenna operating at bandwidths 2.3 to $2.5 \mathrm{GHz}, 3.4$ to 3.6 and 4.25 to $6.85 \mathrm{GHz}$ of size $14 \times 20.5 \times 1.6 \mathrm{~mm}^{3}$. It consists of multiple branches of L-shape and the asymmetric rectangular ground plane comprises of the ACS fed antenna. A Compact ACS-fed MIMO antenna operating at frequencies $5,5.8$ and $6.3 \mathrm{GHz}$ of size $46 \times 26 \mathrm{~mm}^{2}$ is proposed in [22].The antenna consists of meandered radiating patch with rectangular feed line. Similarly, a triple band ACS fed antenna with $\mathrm{M}$ and rectangular shaped radiating branches operating with bandwidths 2.41 to $2.55 \mathrm{GHz}, 3.45$ to $3.65 \mathrm{GHz}$ and 4.6 to $6.3 \mathrm{GHz}$ having a size of $12.5 \times 18 \times 1.6 \mathrm{~mm}^{3}$ is proposed in [23]. Praveen V. Naidu et al. [24] designed a printed V-shaped ACS fed compact dual band antenna of size $14.75 \times 26 \times 1.6 \mathrm{~mm}^{3}$ having resonant frequency of 2.48 and $3.6 \mathrm{GHz}$. A strip of $\mathrm{V}$-shape and a vertical rectangular feedline is used as radiating elements for this antenna.Rajkumar et al. [25] proposed mirrored L-shaped monopole antenna with ACS feed operating at frequencies 2.44, 5.3 and $8.2 \mathrm{GHz}$ having size of $22 \times 16.08 \times 0.8 \mathrm{~mm}^{3}$. Mirrored L-shaped branches and a split ring resonator is taken as the radiating patch. The antenna is designed using $\mathrm{M}$ and L-shaped strips. A rectangular-shaped CSRRs with offset-fed microstrip line is proposed to achieve this operating frequencies.

The above metioned antennas are compact and are multiband in nature. However, the proposed ACS fed antenna in this research work has the advantage of more degree compactness, higher gain, simple configuration, stable radiation pattern and better impedance matching as compared to [16-25]. In the proposed paper, a V-shaped uniplanar triple-band ACS fed antenna has been designed with a size of $26 \times 15 \times 1.6 \mathrm{~mm}^{3}$ at frequencies3.1,5 and $9.9 \mathrm{GHz}$ with corresponding gains of 2.51, 1.18 and $1.96 \mathrm{~dB}$. The resultant shape of the radiating patch is obtained by adding rectangular strips to feed line until desired results are obtained. The fabricated prototype of this antenna operates at 3,5.2 and $9.7 \mathrm{GHz}$, thereby closely micmics the simulated results.

\section{ACS FED ANTENNA DESIGN}

\subsection{Design equation}

The initial dimensions for amonopole antenna with resonant frequency $\left(f_{r}\right)$ is calculated as [6]:

$$
L=\frac{\lambda_{g}}{4}=\frac{c}{4 f_{r} \sqrt{\varepsilon_{e f f}}}
$$

where $\mathrm{L}=$ Length and $\varepsilon_{r}=4.4$. The equations mentioned below are used for the calculation of impedance:

$$
\begin{aligned}
& Z_{0}=\frac{60 \pi}{\sqrt{\varepsilon_{e f f}}} \frac{K(k)}{K\left(k^{\prime}\right)} \\
& \frac{K(k)}{K\left(k^{1}\right)}=\left\{\begin{array}{l}
\frac{\pi}{\ln \frac{2\left(1+\sqrt{\left.k^{1}\right)}\right.}{\left(1-\sqrt{\left.k^{1}\right)}\right.}}, 0 \leq k \leq \frac{1}{\sqrt{2}} \\
\frac{1}{\pi \ln \frac{2(1+\sqrt{k)}}{(1-k)}}, \frac{1}{\sqrt{2}} \leq k \leq 1
\end{array}\right\}
\end{aligned}
$$

where $\varepsilon_{r}$ is the dielectric constant of the material, $\mathrm{k}=\mathrm{a} / \mathrm{b}$ (Length of I major axis/Length of Minor axis). 


\subsection{Design evolution}

An ACS fed antenna for lower frequency ranges, covering WiMAX and WLAN applications, is proposed by evolving the basic structure (configuration "T1") as shown in Figure 1(a). Configuration "T1" corresponds to a basic design consisting of only rectangular ground plane and rectangular feedline in the front plane (uniplanar). For this design two operating frequencies are obtained as depicted in Figure 1(b). To incorporate more number of operating bands "T1" is evolved by adding rectangular strips as shown in configuration "T2" of Figure 1(a). After adding four more strips to configuration "T1" strips ("T2-T5") again dual band is achieved but with higher $S_{11}$ (Figure 1(b)) and gain values resulting in an open $\mathrm{V}$-shaped radiating patch (configuration "T5") in the front plane. The optimization process is carried out for "T5" configuration which leads to closed $\mathrm{V}$-shaped radiating patch hence resulting in proposed structure (configuration "T7"). The proposed ACS fed antenna gives three operating bands at 3.1 (WiMAX), 5.0 (WLAN) and $9.9 \mathrm{GHz}$ (X-band) for $\mathrm{S}_{11}<-10 \mathrm{~dB}$ criteria as illustrated in Figure 1(b). The proposed configuration "T7" is further characterized by conducting parametric analysis in order to achieve stable radiation performances.

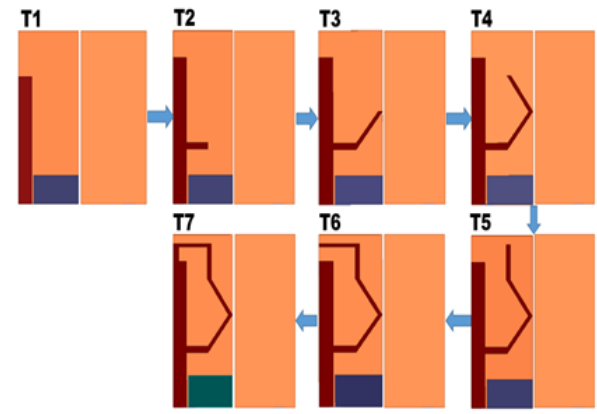

(a)

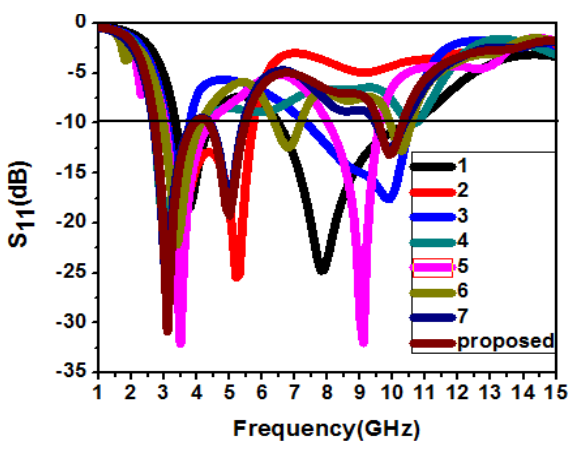

(b)

Figure 1. (a) Evolution stages of corresponding to "T7”, (b) Evolution stage $\mathrm{S}_{11}$ results

The overall design of the proposed uniplanar triple band ACS fed antenna covering WiMAX, WLAN along with X-band is outlined in Figure 2. The antenna consists of closed V-shaped radiating patch with rectangular ground plane in the radiating plane. The antenna is fed using rectangular ACS feed line to achieve an impedance matching of $50 \mathrm{ohm}$.

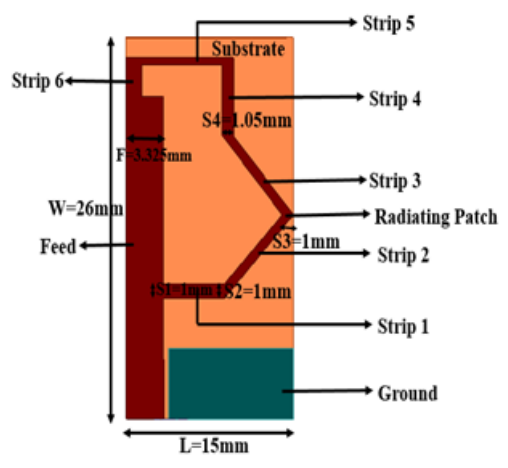

(a)

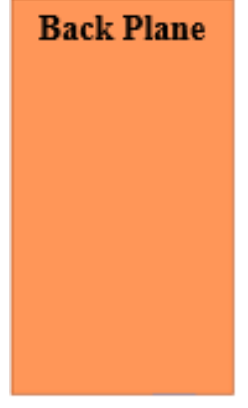

(b)

Figure 2. Proposed “T7” configuration, (a) Front view, (b) Backview

\subsection{Parameteric analysis}

The operational characteristics is observed by performing parametric analysis where the antenna dimensions have been optimized by keeping one dimension constant and varying the other dimension. For operational characteristics optimum values of S1, S2, S3, S4 and F (as shown in Figure 2) are calculated with varying factor as $0.5 \mathrm{~mm}$. The first analysis is carried out by optimizing width of strip 1 (S1) of 
the antenna. Its width is first decreased by $0.5 \mathrm{~mm}$ and then increased by $0.5 \mathrm{~mm}$. The $\mathrm{S}_{11}$ and gain plots of these analysis is depicted in Figure 3(a) and 3(b) respectively. For the $S_{11}$ plot the output is similar for all the three dimensions of of S1. Whereas, from the gain plot it can be observed that for $\mathrm{S} 1=1 \mathrm{~mm}$ the gain is more compared to other two values. Thus in this case $\mathrm{S} 1=1 \mathrm{~mm}$ is taken as the proposed dimension. Similarly, optimization of width of of strip 2 (S2) and strip 3 (S3) is carried out wherein the width is again increased and decreased by $0.5 \mathrm{~mm}$. The $S_{11}$ and gain plots are depicted in Figure 4 and Figure 5 respectively. In this case also the outputs are similar to that of $\mathrm{S} 1$. There is negligible variation for different dimensions of $\mathrm{S} 2$ and $\mathrm{S} 3$ in the $\mathrm{S}_{11}$ plot, as depicted in Figure 4(a) and 5(a). On the other hand, the gain plot gives better result when $S 2=1 \mathrm{~mm}$ and $\mathrm{S} 3=1 \mathrm{~mm}$, as illustrated in Figure $4(\mathrm{~b})$ and $5(\mathrm{~b})$, respectively. Hence $\mathrm{S} 2=\mathrm{S} 3=1 \mathrm{~mm}$ is taken in the proposed structure as the final dimension. In the next step shown in Figure 6 modification in the width of strip 4 (S4) is done, in which the length is again kept constant and width is first increased by $0.5 \mathrm{~mm}$ and then decreased by $0.5 \mathrm{~mm}$ to analyse the results. From the $S_{11}$ and gain plots (Figure 6(a) and 6(b)) it is concluded that $\mathrm{S} 4=1.05 \mathrm{~mm}$ is chosen for the proposed design because it gives minimum return loss while maintaining the acceptable gain. Feed width of the antenna $(\mathrm{F})$ is optimized in the similar manner by increasing and decreasing its width by $0.5 \mathrm{~mm} . \mathrm{S}_{11}$ and gain plots are observed in Figure7 from where it is observed that the proposed dimension gives acceptable results for $\mathrm{F}=3.325 \mathrm{~mm}$. Thus, the final dimensions $(\mathrm{mm})$ of these five important parameters in the proposed structure are: $\mathrm{S} 1=\mathrm{S} 2=\mathrm{S} 3=1, \mathrm{~S} 4=1.05$ and $\mathrm{F}=93.325$.

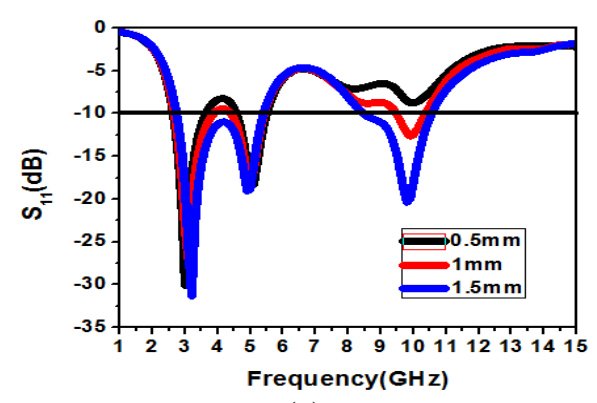

(a)

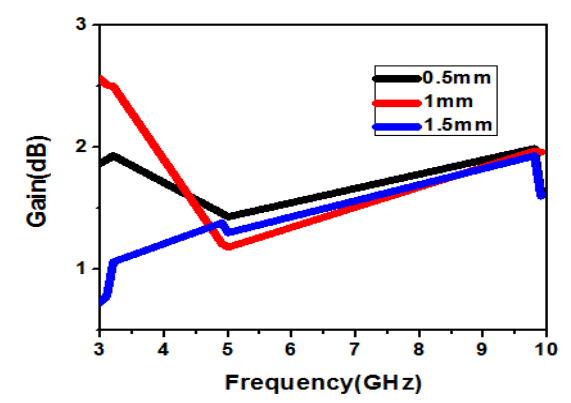

(b)

Figure 3. (a) Impedance bandwidth $\left(\mathrm{S}_{11}\right)$ vs. frequency, (b) Gain vs. frequency for variation in strip 1 (S1)

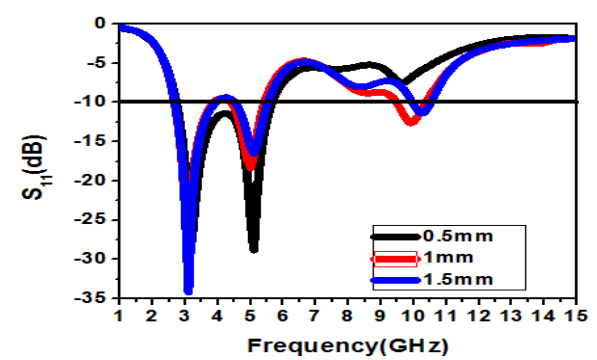

(a)

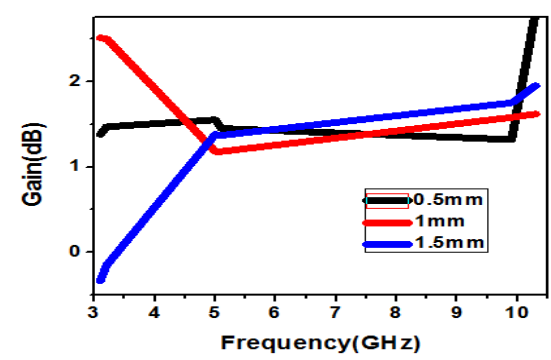

(b)

Figure 4. (a) Impedance bandwidth $\left(\mathrm{S}_{11}\right)$ vs. frequency, (b) Gain vs. frequency for variation in strip 2 (S2)

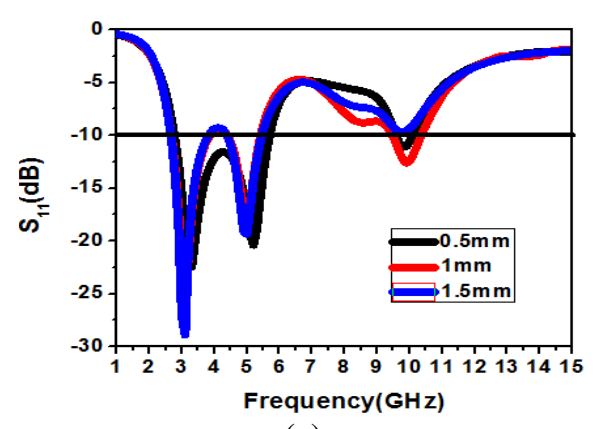

(a)

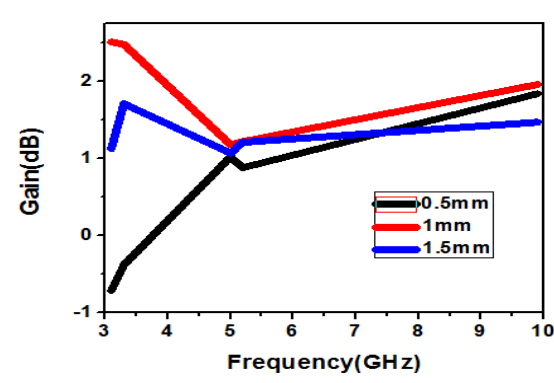

(b)

Figure 5. (a) Impedance bandwidth $\left(\mathrm{S}_{11}\right)$ vs. frequency, (b) Gain vs. frequency for variation in strip 3 (S3) 


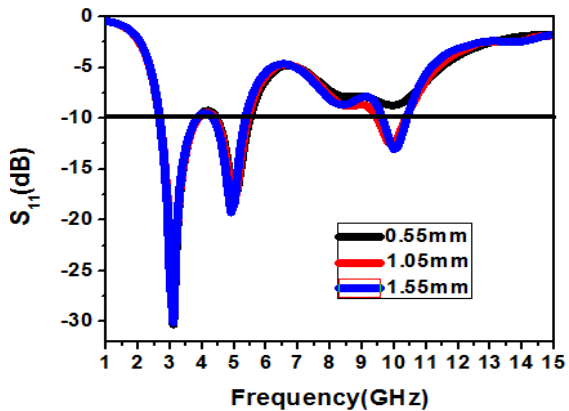

(a)

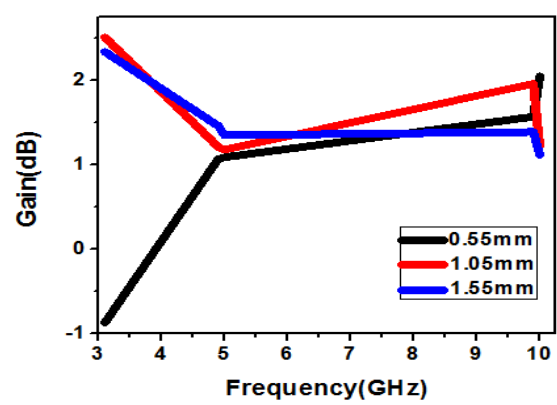

(b)

Figure 6. (a) Impedance bandwidth $\left(S_{11}\right)$ vs. frequency, (b) Gain vs. frequency for variation in strip 4 (S4)

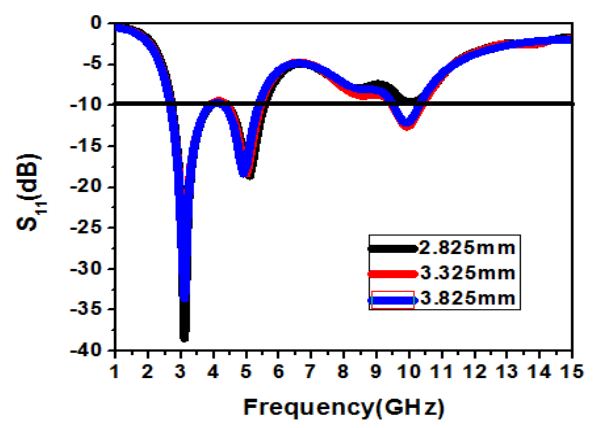

(a)

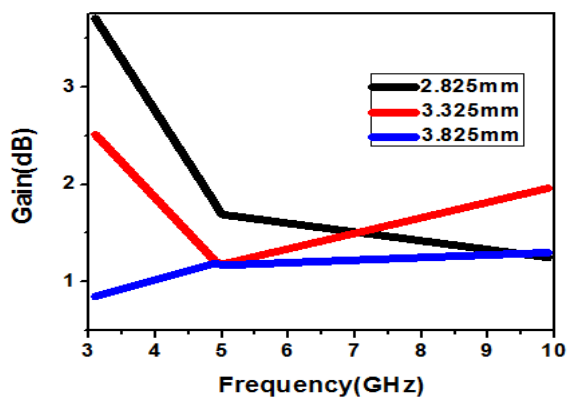

(b)

Figure 7. (a) Impedance bandwidth $\left(\mathrm{S}_{11}\right)$ vs. frequency, (b) Gain vs. frequency for variation in feed width $\mathrm{F}$

\section{RESULTS AND DISCUSSION}

The proposed configuration "T7" is fabricated using photolithographic etching process and the fabricated proptoyupe is depicted in Figure 8. In the simulated and measured $\mathrm{S}_{11}$ result illustrated in Figure 9, it is seen that the antenna shows operation at 3.1, 5 and $9.9 \mathrm{GHz}$ in simulation whereas in measured the fabricated antenna exhibits operation at 3.2, 5.3 and $9.7 \mathrm{GHz}$. The designed antenna has an impedance bandwidth of $1200 \mathrm{MHz}(2.7-3.9 \mathrm{GHz}$, WiMAX), $1100 \mathrm{MHz}$ (4.4-5.5 GHz, WLAN) and $800 \mathrm{MHz}$ (9.5-10.3 GHz, X-band) in simulation. Under measurement the antenna shows a bandwidth of about 900 $\mathrm{MHz}(2.8-3.7 \mathrm{GHz}), 800 \mathrm{MHz}(4.6-5.4 \mathrm{GHz})$ and $600 \mathrm{MHz}$ (9.4-10 GHz). The simulated results complies best with the measured results, however, slight differences in the results may be due to fabrication process, substrate loss and soldering of connectors. The obtained bandwidth is sufficient which can easily meet the demand of WiMAX, WLAN and X-band applications. The detailed results are summarized in Table 1.

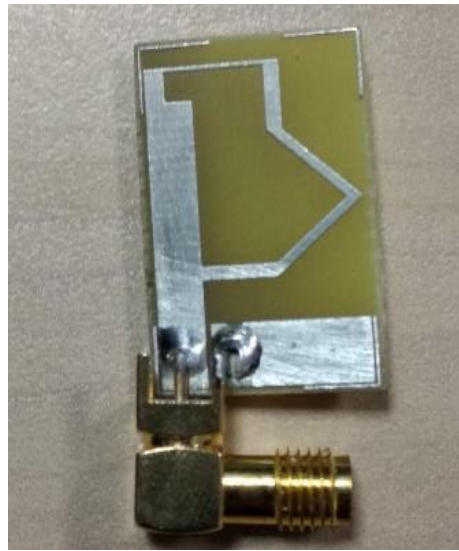

Figure 8. Fabricated prototype of the antenna

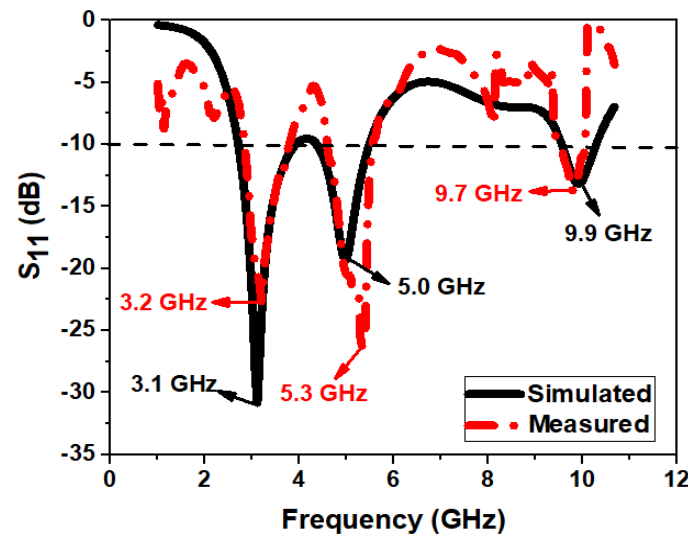

Figure 9. Simulated and measured $\mathrm{S}_{11}$ results 
Table 1. Simulated and measured results of the designed antenna

\begin{tabular}{|c|c|c|c|c|c|c|c|}
\hline Sl. No. & PARAMETER & \multicolumn{3}{|c|}{ SIMULATED RESULTS } & \multicolumn{3}{|c|}{ MEASURED RESULTS } \\
\hline 1. & Frequency $(\mathrm{GHz})$ & 3.1 & 5 & 9.9 & 3.2 & 5.3 & 9.7 \\
\hline 2. & $\mathrm{~S}_{11}(\mathrm{~dB})$ & -30.8 & -19.2 & -13.1 & -22 & -25.8 & -13.8 \\
\hline 3. & Bandwidth (MHz) & 1200 & 1100 & 800 & $900 \mathrm{MHz}$ & $800 \mathrm{MHz}$ & $600 \mathrm{MHz}$ \\
\hline 4. & Applications & WiMAX & WLAN & X-band & WiMAX & WLAN & X-band \\
\hline
\end{tabular}

The simulated 3D gain plot of the designed antenna is illustrated in Figure 10. It can seen that antenna has a total gain of $2.5 \mathrm{~dB}, 1.18 \mathrm{~dB}$ and $1.96 \mathrm{~dB}$ at the operating frequency of $3.1 \mathrm{GHz}, 5.0 \mathrm{GHz}$ and $9.9 \mathrm{GHz}$, respectively.
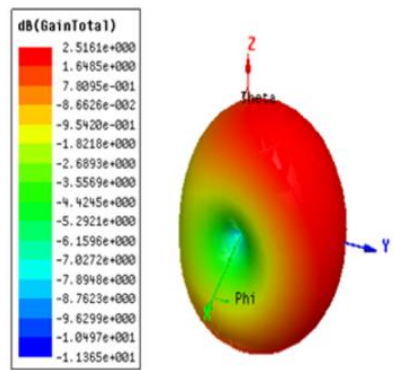

(a)

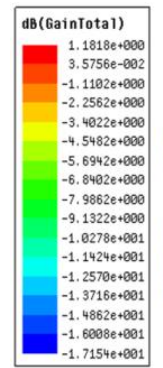

$1.7154+6081$

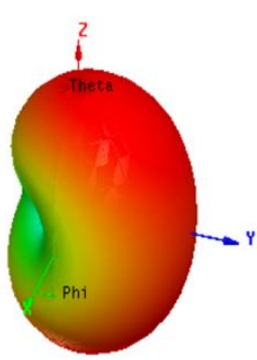

(b)

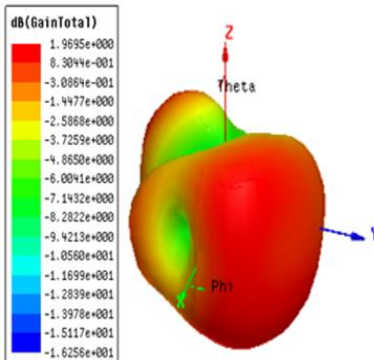

(c)

Figure 10. Gain at the operating frequencies of (a) 3.1 , (b) 5 , (c) $9.9 \mathrm{GHz}$

The Figure 11 shows the surface current distribution at the three operating frequencies 3.1, 5.0 and 9.9 GHz. The scale shows the different colors which are arranged in descending order of the value of current. The regions depicted by red color shows a better current distribution as compared to the ones depicted by yellow, green and so on. It can be analysed for $3.1 \mathrm{GHz}$ the current arount strip lenth 1,2 and 5 is more concentrated. For $5.0 \mathrm{GHz}$, the current is denser around the lenth of strip 2, 3 and 5. For $9.9 \mathrm{GHz}$ the current covers the entire closed V-shaped path. The simulated radiation patterns of the proposed antenna at the three operating frequencies 3.1, 5 and $9.9 \mathrm{GHz}$ is illustrated in Figure 12. The antenna has bi-directional radiation pattern and omnidirectional pattern in $\mathrm{E}\left(\varphi=0^{\circ}\right)$ and $\mathrm{H}$-plane $\left(\varphi=90^{\circ}\right)$ respectively.

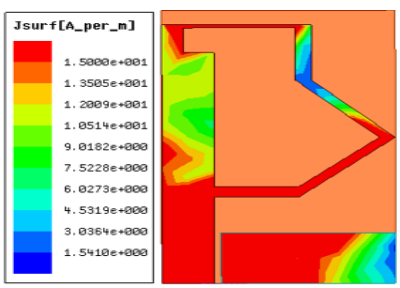

(a)

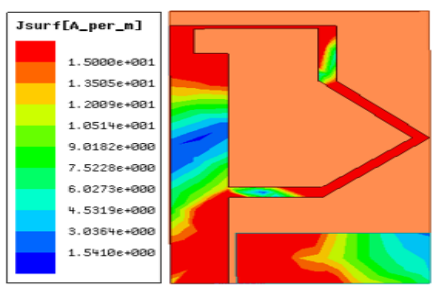

(b)

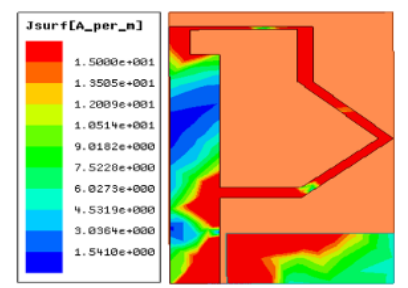

(c)

Figure 11. Current distribution at the operating frequencies of (a) 3.1 , (b) 5 , (c) $9.9 \mathrm{GHz}$

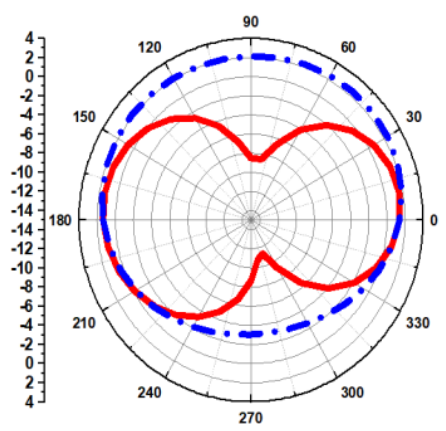

(a)

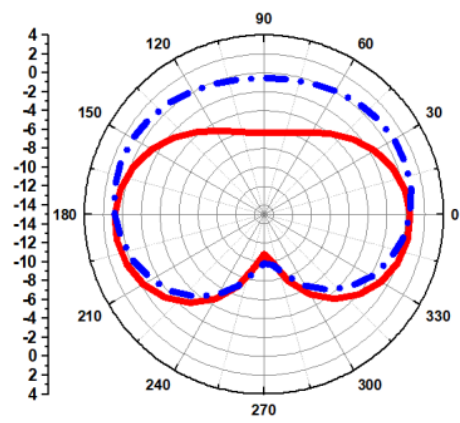

(b)

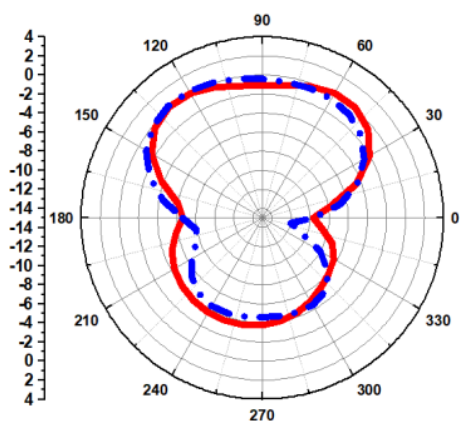

(c)

Figure 12. Simulated radiation patterns at (a) 3.1 , (b) 5 , (c) $9.9 \mathrm{GHz}$ (blue line- $\varphi=0^{\circ}$ and red line- $\varphi=90^{\circ}$ ) 
A comparative analysis is done between the proposed antenna and the similar type present in the literature. The Table 2 exhibhits that the proposed ACS fed antenna has several advantages over its counterparts.

Table 2. Comparative analysis of the proposed ACS fed antennas with the similar types in the literature

\begin{tabular}{cccccc}
\hline Ref. & Patch Size $\left(\mathrm{mm}^{2}\right)$ & No. of bands & $\begin{array}{c}\text { Operating } \\
\text { Frequencies }(\mathrm{GHz})\end{array}$ & $\begin{array}{c}\text { Operating Bandwidth } \\
(\mathrm{GHz})\end{array}$ & Applications \\
\hline$[16]$ & $14 \times 20$ & 3 & $2.35 / 3.5 / 5.25$ & $2.3-2.4 / 3.4-3.55 / 4.15-6.6$ & WLAN/WiMAX \\
{$[17]$} & $60 \times 36$ & 2 & $3.6 / 5.4$ & $3.4-3.8 / 5.15-5.6$ & WLAN/WiMAX \\
{$[18]$} & $19.1 \times 22.6$ & 3 & $2 / 3 / 5.2$ & $1.86-1.91 / 2.89-2.98 / 4.96-6.78$ & WLAN/WiMAX \\
{$[19]$} & $11.5 \times 26$ & 3 & $2.35 / 3.5 / 5.2$ & $2.28-2.46 / 3.33-3.6 /(5.05-5.4$ & WLAN/WiMAX \\
{$[20]$} & $25 \times 17.5$ & 2 & $2.45 / 5$ & $2.30-2.55 / 4.06-6.65$ & Bluetooth/WLAN \\
{$[21]$} & $14 \times 20.5$ & 3 & $2.4 / 3.5 / 5.5$ & $2.3-2.5 / 3.4-3.6 / 4.25-6.85$ & WLAN/WiMAX \\
{$[22]$} & $46 \times 26$ & 3 & $5 / 5.8 / 6.3$ & $4.75-5.25 / 5.76-5.83 / 6.27-6.33$ & WLAN/WiMAX \\
{$[23]$} & $12.5 \times 18$ & 3 & $2.45 / 3.5 / 5.5$ & $2.41-2.55 / 3.45-3.65 / 4.6-6.5$ & WLAN/WiMAX \\
{$[24]$} & $14.75 \times 26$ & 2 & $2.48 / 3.6$ & $2.38-3.95 / 3.3-4.2$ & WiMAX/WLAN \\
{$[25]$} & $22 \times 16.08$ & 3 & $2.44 / 5.30 / 8.2$ & $2.3-2.53 / 5.18-5.85 / 8-8.53$ & WiMAX/WLAN \\
Prop. & $19 \times 10$ & 3 & $5.6 / 8.2 / 12.6$ & $5.2-6.2 / 7.52-8.6 / 9.4-13.5$ & WLAN/X-Band \\
\hline
\end{tabular}

\section{CONCLUSION}

A triple band ACS fed antenna of size $26 \times 15 \times 1.6 \mathrm{~mm}^{3}$ is simulated and fabricated which shows operation at 3.2, 5.3 and $9.7 \mathrm{GHz}$, thus covering WiMAX, WLAN and X-band applications. The simulated $\mathrm{S}_{11}$ and field parameters of the antenna closely mimics the fabricated prototype results which are evaluated using VNA (vector network analyzer). All the three bands exhibit good impedance matching and accepatable gains. The designed antenna has the advantage of compact size, uniplanr simple structure and exhibhits good radiational performance which can esily meet the demand of the aforementioned applications.

\section{REFERENCES}

[1] M. S. Islam, et al.,"Microstrip patch antenna with defected ground structure for biomedical application," Bulletin of Electrical Engineering and Informatics, vol. 8, no. 2, pp. 586-595, Jun 2019.

[2] T. Ali, et al.,"A miniaturized multiband reconfigurable fractal slot antenna for GPS/GNSS/Bluetooth/WiMAX/Xband applications," AEU-International Journal of Electronics and Communications, vol. 94, pp. 234-243, 2018.

[3] T. Ali, et al.,"A miniaturized slotted ground structure UWB antenna for multiband applications," Microwave and Optical Technology Letters, vol. 60, no. 8, pp. 2060-2068, Aug 2018.

[4] A. A. Jabber andR. H. Thaher, "Compact tri-band T-shaped frequency reconfigurable antenna for cognitive radio applications," Bulletin of Electrical Engineering and Informatics, vol. 9, no. 1, pp. 212-220, Feb 2020.

[5] A. R. O. Mumin, et al.,"Design a compact square ring patch antenna with AMC for SAR reduction in WBAN applications," Bulletin of Electrical Engineering and Informatics, vol. 9, no. 1, pp. 370-378, Feb 2020.

[6] C. A. Balanis, "Antenna theory: analysis and design," John wiley \& sons, 2016.

[7] T. Ali, et al.,"A novel metamaterial rectangular CSRR with pass band characteristics at 2.95 and $5.23 \mathrm{GHz}$,"in 2017 2nd IEEE International Conference on Recent Trends in Electronics, Information \& Communication Technology (RTEICT), pp. 256-260, 2017.

[8] O. Rasheed, et al.,"Bandwidth and gain enhancement of a circular microstrip antenna using a DNG split ring resonator radome," Bulletin of Electrical Engineering and Informatics, vol. 8, no. 2, pp. 637-643, Jun 2019.

[9] C. M. N. C. Isa, et al.,"User's hand effect on efficiency of 2-port 5 GHZ mobile terminal antennas," Bulletin of Electrical Engineering and Informatics, vol. 8, no. 2, pp. 604-610, Jun 2019.

[10] Y. Li, et al.,"12-port 5G massive MIMO antenna array in sub-6GHz mobile handset for LTE bands 42/43/46 applications," IEEE access, vol. 6, pp. 344-354, 2018.

[11] Naidu, P. V., et al., "Uniplanar ACS fed multiband high-gain antenna with extended rectangular strips for portable system applications", International Journal of RF and Microwave Computer Aided Engineering, vol. 29, no. 10, 2019.

[12] X. Li, et al.,"Compact triband ACS-fed monopole antenna employing open-ended slots for wireless communication,"IEEE Antennas andWirelessPropagation Letters, vol. 12, pp. 388-391, Jan 2013.

[13] V. Deepu, et al.,"Compact asymmetric coplanar strip fed monopole antenna for multiband applications," IEEE Transactions on Antennas and Propagation, vol. 55, no. 8, pp. 2351-2358, Aug 2007.

[14] X. Sun, et al.,"A compact quadband CPW-fed slot antenna for M-WiMAX/WLAN applications," IEEE Antennas and Wireless Propagation Letters, vol. 11, pp. 395-398, 2012.

[15] L. Chen, et al., "Compact ACS-fed circular-arc-shaped stepped monopole antenna for tri-band WLAN/WIMAX applications,"Progress in Electromagnetics Research C, vol. 51, pp. 131-137, Jan 2014.

[16] P. V. Naidu, et al.,"Uniplanar Y and L shaped ACS fed multiband and wideband compact printed antenna for advanced wireless communication systems," Microsystem Technologies, vol. 24, no. 4, pp. 2051-2061, 2018.

[17] B. Mishra, et al.,"Dual and wide-band slot loaded stacked microstrip patch antenna for WLAN/WiMAX applications," Microsystem Technologies, vol. 23, no. 8, pp. 3467-3475, 2017. 
[18] R. S. Daniel, et al., "Offset-fed complementary split ring resonators loaded monopole antenna for multiband operations," AEU-International Journal of Electronics and Communications, vol. 78, pp. 72-78, 2017.

[19] P. V. Naidu and A. Kumar, "A novel ACS fed multi band antenna loaded with mirrored S and L shaped strips for advanced portable wireless communication applications," Microsystem Technologies, vol. 23, no. 10, pp. 4775-4783, 2017.

[20] K. A. Ansal and T. Shanmuganantham, "A novel CB ACS-fed dual band antenna with truncated ground plane for 2.4/5 GHz WLAN application," AEU-International Journal of Electronics and Communications, vol. 69, no. 10, pp. 1506-1513, Oct 2015.

[21] A. Kumar, et al." "A compact uniplanar ACS fed multi band low cost printed antenna for modern 2.4/3.5/5 GHz applications," Microsystem Technologies, vol. 24, no. 3, pp. 1413-1422, 2018.

[22] A. A. Ibrahim, et al.,"Compact ACS-fed CRLH MIMO antenna for wireless applications," IET Microwaves, Antennas \& Propagation, vol. 12, no. 6, pp. 1021-1025, 2018.

[23] P. V. Naidu and A. Kumar, "Design and development of triple band ACS fed antenna with M and rectangular shaped radiating branches for $2.45 / 5 \mathrm{GHz}$ wireless applications," Microsystem Technologies, vol. 23, no. 4, pp. 5841-5848, 2017.

[24] P. V. Naidu, "Printed V-shape ACS-fed compact dual band antenna for bluetooth, LTE and WLAN/WiMAX applications," Microsystem Technologies, vol. 23, no. 4, pp. 1005-1015, 2017.

[25] R. Rajkumar and U. K. Kommuri, "A compact ACS-fed mirrored L-shaped monopole antenna with SRR loaded for multiband operation," Progress In Electromagnetics Research C, vol. 64, pp. 159-167, 2016.

\section{BIOGRAPHIES OF AUTHORS}

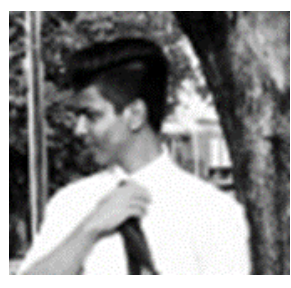

Anuj Kumar is pursuing B-Tech $\left(8^{\text {th }}\right.$ semester) in Electronics \& Communication Engineering at Manipal Institute of Technology, Manipal Academy of Higher Education, Manipal, Karnataka576104. His research area intrests are wideband antennas, UWB and SWB antennas, multiband antennas, Dielectric resonator antennas for $5 \mathrm{G}$ communications etc

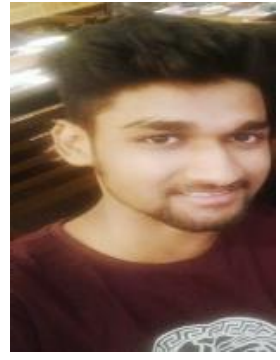

Anukul Jindal, is pursuing B-Tech $\left(6^{\text {th }}\right.$ semester $)$ in Electronics \& Communication Engineering at Manipal Institute of Technology, Manipal Academy of Higher Education, Manipal, Karnataka-576104. His research area intrests are wideband antennas, UWB and SWB antennas, multiband antennas, Dielectric resonator antennas for $5 \mathrm{G}$ communications etc

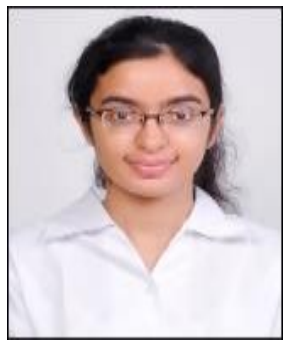

Apurva Singh, is working as a Graduate Engineer Trainee at KPIT Technologies Research and Development Wing at Bangalore India. She has authored numerous research paper in many peerreviewed high impact factor journals. Her research area intrests are wideband antennas, UWB and SWB antennas, multiband antennas, Dielectric resonator antennas for 5G communications etc.

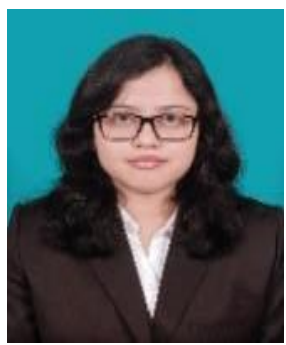

Reshma Roy, is working as a Project Engineer at Wipro Research and Development Wing at Bangalore India. She has authored several research paper in many peer-reviewed high impact factor journals. Her research area intrests are metamaterial antennas, UWB antennas, multiband antennas, wireless power transfer, near field communications etc. 


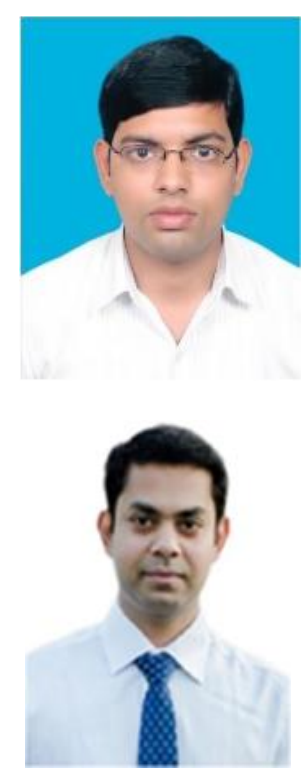

Om Prakash Kumar is an Assistant Professor in the Dept. of Electronics \& Communication Engineering at Manipal Institute of Technology, Manipal Academy of Higher Education, Manipal. He has authored more than 20 research article in high impact factor SCI journals. His research field includes UWB Antennas, Multiband antennas and metamaterial antennas.

Tanweer Ali is working as Assistant Professor in the Department of Electronics \& Communication Engineering at Manipal Instituteof Technology, Manipal Academy of Higher Education, Manipal. He is an active researcher in the field of microstrip antennas, wireless communication and microwave Imaging. He has published more than 65 papers in reputed peer reviewed international journal and conferences. He is a senior member IEEE (SMIEEE), and Associate Member of IETE India. He is on the board of reviewers of journals like the IEEE Transactions on Antennas and Propagation, IEEE Antennas and Wireless Propagation Letters, IET Microwaves, Antennas \& Propagation, IET Electronics letter, Wireless Personal Communication (WPC), Springer, AEU-International Journal of Electronics and Communications, Microwave and optical Technology letters (MOTL), Wiley, International Journal of Antennas and Propagation, Hindawi., Advanced Electromagnetics, Progress in Electromagnetic Research (PIER), KSII Transaction ofEngineering Science, Korea, International Journal of Microwave andWireless Technologies, Frequenz, Radio engineering etc. 